\title{
REVIEW ARTICLE Recent Topics in Fetal Echocardiography
}

\author{
Toshiyuki Hata ${ }^{1}$, Aya Koyanagi ${ }^{2}$, Riko Takayoshi ${ }^{3}$, Takahito Miyake ${ }^{4}$
}

\begin{abstract}
Recent advances in fetal echocardiography are HDlive Flow (silhouette) and FetalHQ. HDlive Flow (silhouette) provides novel visual experiences for operators due to the spatial visualization of fetal cardiac structures and allows examiners to easily understand the spatial relationships among fetal cardiac chambers, great arteries, and veins. HDlive Flow (silhouette) may become an important diagnostic tool for the assessment of the normal fetal heart and congenital heart anomaly. FetalHQ consists of a 24-segment sphericity index (SI) and fractional shortening (FS). Fetal 24-segment SI can measure cardiac remodeling and the diastolic shape, whereas 24-segment FS can evaluate the fetal cardiac function and ventricular contractility. Fetal 24-segment SI and FS using FetalHQ may become useful diagnostic modalities in clinical practice. In this review article, we present the latest state-of-the-art HDlive Flow (silhouette) and FetalHQ of normal and abnormal fetal hearts. We also discuss the present and future applicability of these novel techniques to assess normal and abnormal fetal hearts. HDlive Flow (silhouette) and FetalHQ may become important modalities in future research on the fetal heart.
\end{abstract}

Keywords: 24-segment fractional shortening, 24-segment sphericity index, Congenital heart anomaly, Fetal heart, FetalHQ, HDlive Flow, HDlive flow silhouette.

Donald School Journal of Ultrasound in Obstetrics and Gynecology (2021): 10.5005/jp-journals-10009-1717

\section{INTRODUCTION}

Several studies have employed HDlive Flow (silhouette) with spatiotemporal image correlation (STIC) to investigate the normal heart and fetal cardiac anomalies. ${ }^{1-14}$ HDlive Flow enables increased depth perception due to the incorporation of an adjustable light source that has lighting and shadowing effects in three-dimensional (3D)/four-dimensional (4D) color/ power Doppler ultrasound. ${ }^{2,5}$ HDlive Flow silhouette facilitates vitreous-like clearness of blood flow and preserves the outline and borders of blood flow, while simultaneously presenting the core as semitransparent. ${ }^{5}$ Thus, it enables holographic 3D fetal heart reconstruction.

The 24-segment sphericity index (SI) was developed by DeVore et al. ${ }^{15}$ as a novel approach for assessing the fetal cardiac diastolic shape using FetalHQ TM GE (Voluson E10, GE Healthcare, Zipf, Austria) with the speckle-tracking technique. Twenty-foursegment fractional shortening (FS) was also described as a method for investigating fetal cardiac function for the first time by DeVore et al. ${ }^{16}$

Here, the most up-to-date state-of-the-art HDlive Flow (silhouette) and 24-segment SI and FS using Feta/HQ of normal and abnormal fetal hearts are presented. Present and future applications of these techniques are also considered to examine the normal and abnormal fetal heart.

\section{HDlive Flow}

\section{Normal Heart}

The anatomical structures of the normal fetal heart were reconstructed from unique $3 \mathrm{D}$ cardiac views using HDlive Flow (silhouette) with STIC facilities assessments by examiners. ${ }^{8,9}$

\section{Frontal View}

Spatial relationships between the right atrium and superior and inferior vena cava are shown in the frontal view (Fig. 1).

\footnotetext{
1,4 Department of Obstetrics and Gynecology, Miyake Clinic, Okayama, Japan; Department of Perinatology and Gynecology, Kagawa University Graduate School of Medicine, Kagawa, Japan

2,3 Department of Obstetrics and Gynecology, Miyake Clinic, Okayama, Japan
}

Corresponding Author: Toshiyuki Hata, Department of Obstetrics and Gynecology, Miyake Clinic, Okayama, Japan; Department of Perinatology and Gynecology, Kagawa University Graduate School of Medicine, Kagawa, Japan, Phone: +81-(0)87-891-2174, e-mail: toshi28@med.kagawa-u.ac.jp

How to cite this article: Hata T, Koyanagi A, Takayoshi R, et al. Recent Topics in Fetal Echocardiography. Donald School J Ultrasound Obstet Gynecol 2021;15(3):259-265.

Source of support: Nil

Conflict of interest: None

The inflow view of the right atrium (from the superior and inferior vena cava to the right atrium) may be evaluated from the frontal view. "Good", "Fair", and "Poor" success rates using the frontal view were $47.7,45.5$, and $6.8 \%$, respectively, at $18-21$ weeks of gestation and $47.7,50.8$, and $1.5 \%$, respectively, at 28-31 weeks. ${ }^{12}$

\section{Spatial Three-vessel View}

The relationships and course of outflow tracts (crisscross arrangements of the pulmonary artery and aorta) and the superior vena cava may be visualized using the spatial three-vessel view (Fig. 2). The crisscross arrangements of the aorta, pulmonary artery, and superior vena cava are clearly displayed in the spatial three-vessel view. "Good", "Fair", and "Poor" success rates using the spatial three-vessel view were $95.5,4.5$, and $0 \%$, respectively, at $18-21$ weeks of gestation and $98.5,1.5$, and $0 \%$, respectively, at 28-31 weeks. ${ }^{12}$ The "Good" success rate was significantly higher 


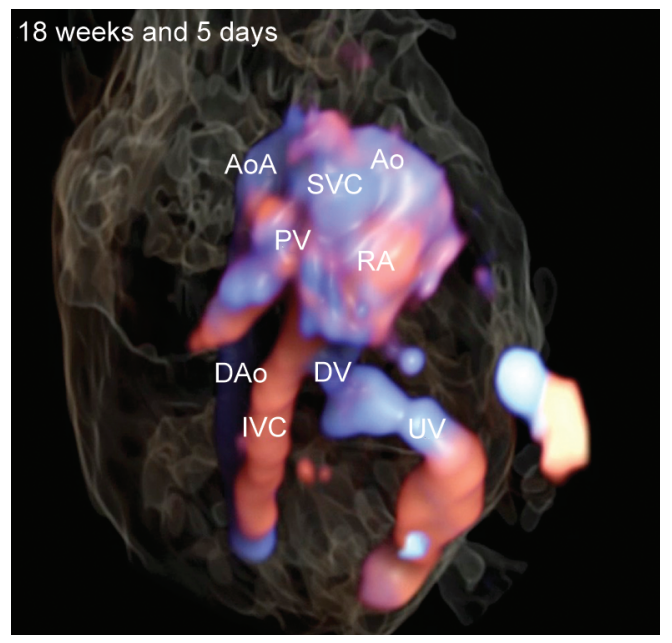

Fig. 1: Frontal view with HDlive Flow of a normal fetal heart at 18 weeks and 5 days of gestation. Ao, aorta; AoA, aortic arch; DAo, descending aorta; DV, ductus venosus; IVC, inferior vena cava; PV, pulmonary vein; RA, right atrium; SVC, superior vena cava; UV, umbilical vein

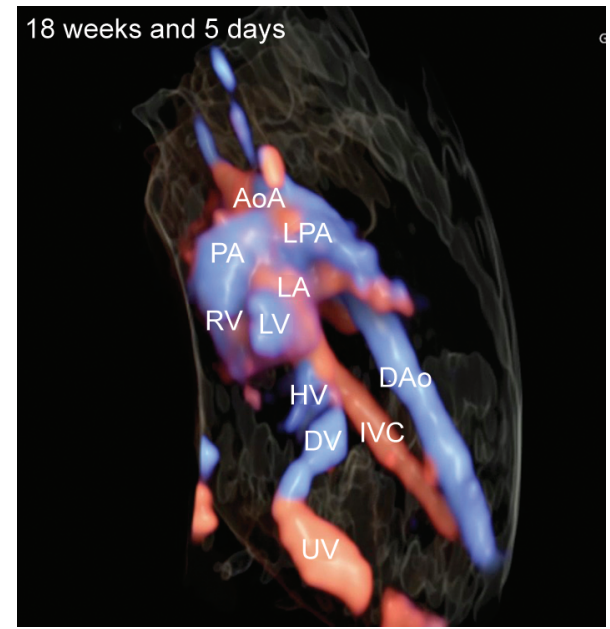

Fig. 3: Panoramic view with HDlive Flow of a normal fetal heart at 18 weeks and 5 days of gestation. AoA, aortic arch; DAo, descending aorta; DV, ductus venosus; HV, hepatic vein; IVC, inferior vena cava; LA, left atrium; LPA, left pulmonary artery; LV, left ventricle; PA, pulmonary artery; RV, right ventricle; UV, umbilical vein

with the spatial three-vessel view than with other cardiac views at 18-21 and 28-31 weeks of gestation. ${ }^{12}$

\section{Panoramic View}

Spatial relationships among cardiac chambers and vessels are displayed in the panoramic view, which increases the ease by which these relationships as well as the courses of the outflow and inflow tracts may be visualized (Fig. 3). The panoramic view comprises left, oblique, and lateral views, in which two ventricles, two great arteries, and the descending aorta are clearly shown. "Good", "Fair", and "Poor" success rates using the panoramic view were 43.2, 54.5, and $2.3 \%$, respectively, at $18-21$ weeks of gestation and $46.2,52.3$, and $1.5 \%$, respectively, at $28-31$ weeks. ${ }^{12}$

\section{Posterior View}

The vertical descending aorta was clearly visualized in the posterior view, and it was also possible to observe the right atrium and

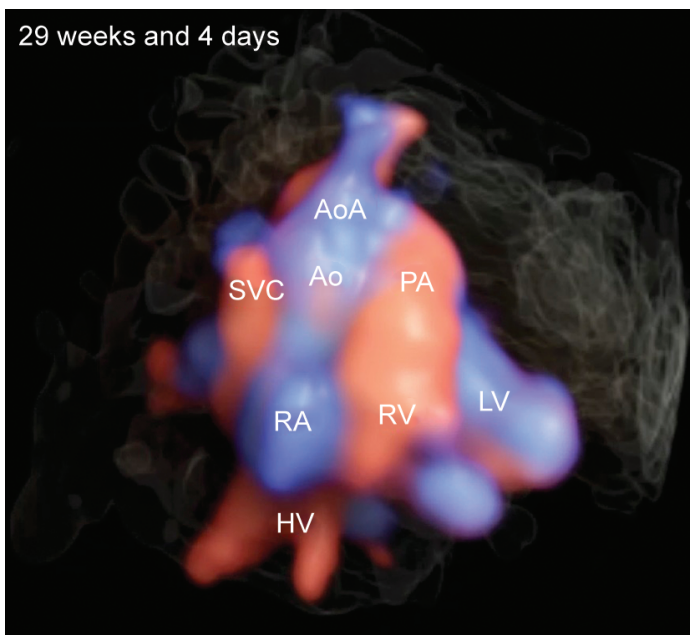

Fig. 2: Spatial three-vessel view with HDlive Flow of a normal fetal heart at 29 weeks and 4 days of gestation. Ao, aorta; AoA, aortic arch; HV, hepatic vessel; LV, left ventricle; $P A$, pulmonary artery; RA, right atrium; $\mathrm{RV}$, right ventricle; SVC, superior vena cava

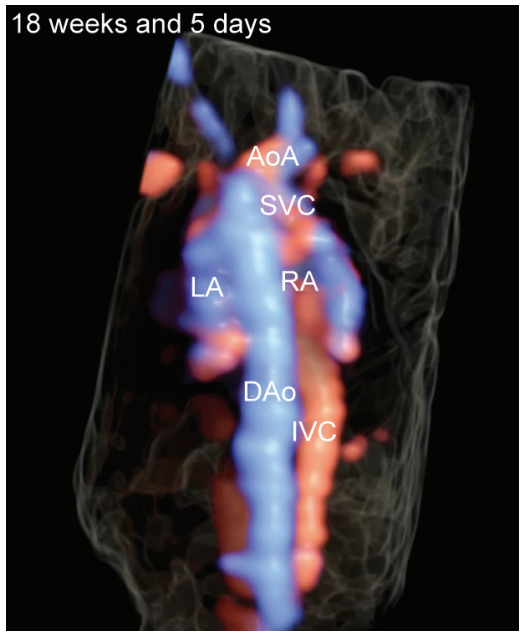

Fig. 4: Posterior view with HDlive Flow of a normal fetal heart at 18 weeks and 5 days of gestation. AoA, aortic arch; DAo, descending aorta; IVC, inferior vena cava; LA, left atrium; RA, right atrium; SVC, superior vena cava

superior and inferior vena cava (Fig. 4). "Good", "Fair", and "Poor" success rates using the posterior view were $45.5,47.7$, and $6.8 \%$, respectively, at $18-21$ weeks of gestation and $46.2,50.8$, and $3 \%$, respectively, at 28-31 weeks. ${ }^{12}$

\section{Right Lateral View}

The aortic arch, descending aorta, and superior and inferior vena cava were visualized in the right lateral view (Fig. 5). Assessments of the aortic arch are typically conducted in this view. "Good", "Fair", and "Poor" success rates using the right lateral view were 47.7, 45.5, and $6.8 \%$, respectively, at $18-21$ weeks of gestation and $47.7,50.8$, and $1.5 \%$, respectively, at $28-31$ weeks. $^{12}$

\section{Congenital Heart Anomaly}

The visualization of spatial relationships among fetal cardiac chambers, great arteries, and veins is facilitated by HDlive Flow (silhouette), which also displays the different sizes of the great vessels. Therefore, it is possible to obtain a detailed understanding 


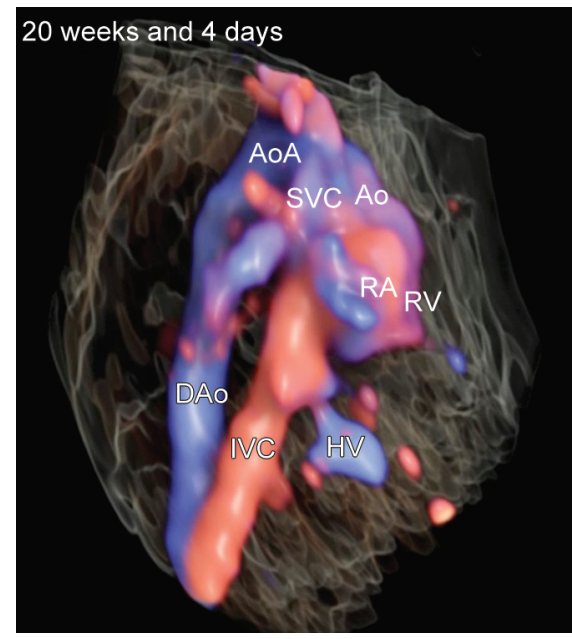

Fig. 5: Right lateral view with HDlive Flow of a normal fetal heart at 20 weeks and 4 days of gestation. Ao, aorta; AoA, aortic arch; DAo, descending aorta; HV, hepatic vein; IVC, inferior vena cava; RA, right atrium; RV, right ventricle; SVC, superior vena cava

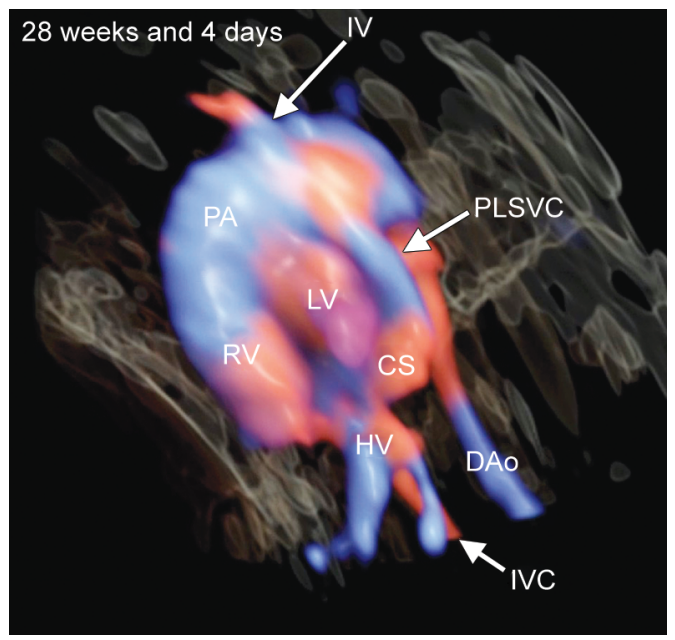

Fig. 7: Panoramic view of absent right superior vena cava and persistent left superior vena cava (PLSVC) at 28 weeks and 4 days of gestation. CS, coronary sinus; DAo, descending aorta; HV, hepatic vein; IV, innominate vein; IVC, inferior vena cava; LV, left ventricle; PA, pulmonary artery; RV, right ventricle. (Courtesy: Reprinted with permission from Jaypee Brothers Medical Publishers (P) Ltd. $)^{13}$

of complex cardiac structures in congenital heart diseases. Holographic images of the fetal heart with hidden vessels, including the descending aorta and several veins, may be obtained using HDlive Flow silhouette. ${ }^{5,8,9}$

A persistent left superior vena cava (PLSVC) was clearly observed on the left side of the pulmonary artery of a fetus using the spatial three-vessel view (Fig. 6). ${ }^{8}$

Persistent left superior vena cava with an absent right superior vena cava (ARSVC) connected to a dilated coronary sinus was visualized in five separate cardiac views provided by HDlive Flow with STIC (Figs 7 and 8). ${ }^{13}$

A large main pulmonary artery in a fetus due to post-stenotic dilatation in the presence of pulmonary stenosis (PS) was using a spatial three-vessel view. ${ }^{13}$ The large pulmonary artery was also observed in the posterior view (Fig. 9).

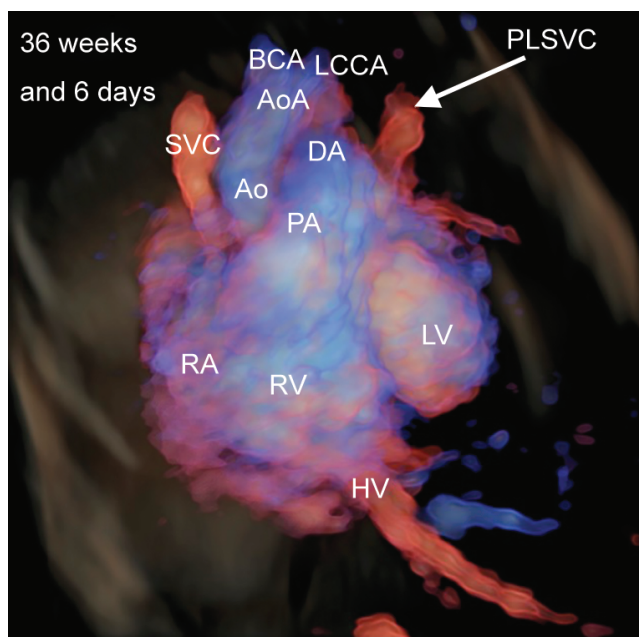

Fig. 6: Spatial three-vessel view of persistent left superior vena cava (PLSVC) depicted by HDlive Flow silhouette at 36 weeks and 6 days of gestation. Ao, aorta; AoA, aortic arch; BCA, brachiocephalic artery; HV, hepatic vein; LV, left ventricle; LCCA, left common carotid artery; PA, pulmonary artery; RA, right atrium; RV, right ventricle; SVC, superior vena cava. (Courtesy: Reprinted with permission from Jaypee Brothers Medical Publishers (P) Ltd. $)^{8}$

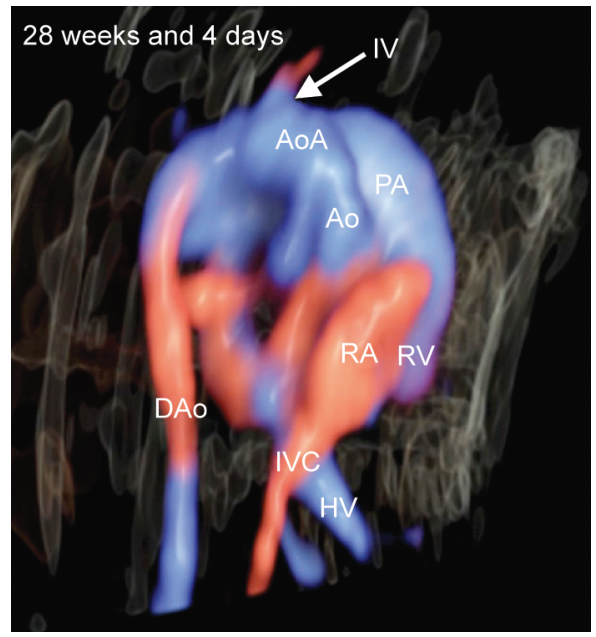

Fig. 8: Right lateral view of absent right superior vena cava and persistent left superior vena cava at 28 weeks and 4 days of gestation. Ao, aorta; AoA, aortic arch; DAo, descending aorta; HV, hepatic vein; IV, innominate vein; IVC, inferior vena cava; PA, pulmonary artery; RV, right ventricle. (Courtesy: Reprinted with permission from Jaypee Brothers Medical Publishers (P) Ltd. $)^{13}$

HDlive Flow with STIC of a fetus with a double outlet right ventricle (DORV) revealed a large aorta and small pulmonary artery leaving the right ventricle in parallel (Fig. 10). Spatial anomalies in the courses of the aortic arch and descending aorta were also detected. ${ }^{14}$

\section{FETALHQ}

\section{4-segment SI}

The speckle-tracking technique automatically traced the endocardial border of each ventricle in the four-chamber view provided by two-dimensional (2D) sonography, and FetalHQ was used to automatically calculate the 24-segment SI of each ventricle 


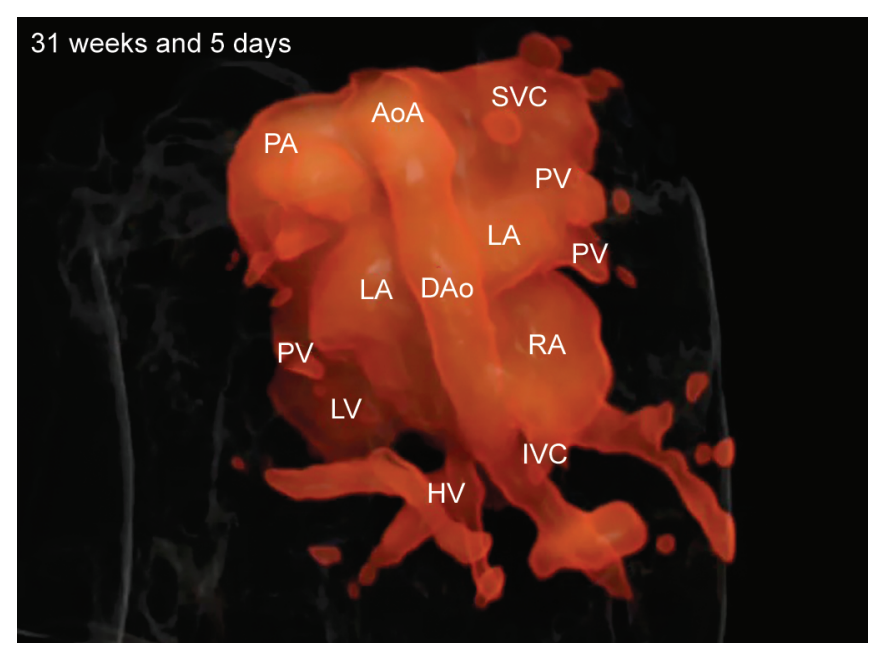

Fig. 9: Posterior view with HDlive Flow silhouette of pulmonary stenosis at 31 weeks and 5 days of gestation. AoA, aortic arch; DAo, descending aorta; HV, hepatic vein; IVC, inferior vena cava; LA, left atrium; LV, left ventricle; PA, pulmonary artery; RA, right atrium; PV, pulmonary vein; SVC, superior vena cava. (Courtesy: Reprinted with permission from Jaypee Brothers Medical Publishers (P) Ltd. $)^{9}$

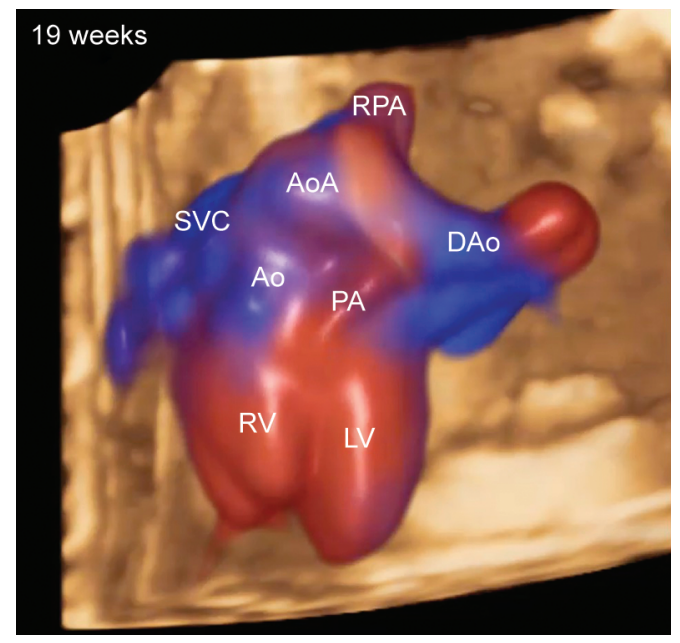

Fig. 10: HDlive Flow image of double outlet right ventricle (spatial three-vessel view) at 19 weeks of gestation. A parallel arrangement of great arteries is clearly recognized. Ao, aorta; AoA, aortic arch; DAo, descending artery; LV, left ventricle; PA, pulmonary artery; RPA, right pulmonary artery; RV, right ventricle; SVC, superior vena cava. (Courtesy: Reprinted with permission from Jaypee Brothers Medical Publishers (P) Ltd. $)^{14}$

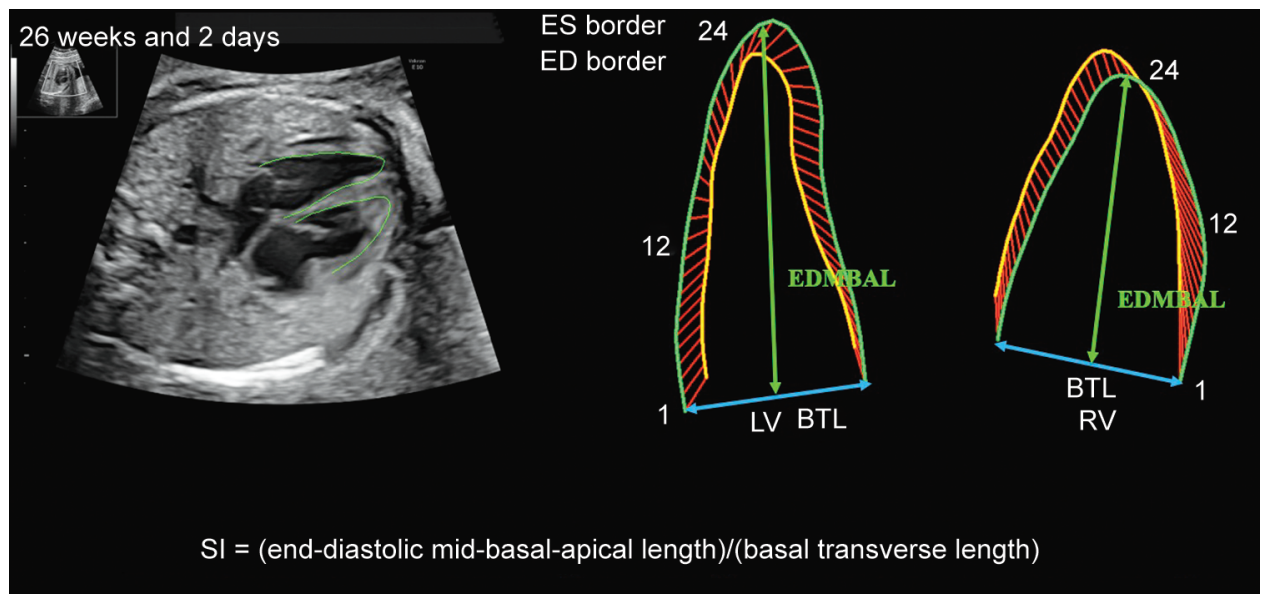

Fig. 11: Measurement of 24-segment sphericity index (SI) at 26 weeks and 2 days of gestation. BTL, basal transverse length; EDMBAL, end-diastolic mid-basal-apical length; LV, left ventricle: RV, right ventricle

(Fig. 11). ${ }^{15,17}$ Twenty-four-segment SI is obtained by dividing the end-diastolic mid-basal-apical length by each transverse length. ${ }^{15}$

Stroke volume is maintained in cases of fetal growth restriction (FGR) by three different phenotypes of cardiomegaly (elongated, globular, and hypertrophic), with changes in these phenotypes reflecting increases in disease severity. ${ }^{18}$ The hypertrophic phenotype is associated with early-onset FGR and the globular and elongated phenotypes with late-onset FGR. ${ }^{18}$ Fetal growth restriction fetuses with abnormal SI are more frequently detected using fetal 24-segment SI than basal segment SI. ${ }^{19}$ Fetal cardiac remodeling assessed using SI has been reported in a significantly high proportion of pregnancies complicated by late-onset FGR and is affected by a high burden of short-term perinatal compromise. ${ }^{20}$ The $\mathrm{SI}$ has been proposed as a more stable and reproducible measurement than functional parameters. ${ }^{21}$

The four-chamber view in fetuses with coarctation of the aorta was found to be spherical based on 24-segment $\mathrm{SI}^{22}$ and, thus, may be used to prenatally differentiate between fetuses suspected of having coarctation of the aorta and those who do not. ${ }^{23}$

Hata et al. ${ }^{24}$ found that the reliability of 24 -segment SI measurements of the fetal heart was low even among experienced sonographers. Therefore, further training on how to accurately place the three end-systolic and-diastolic reference points during the initial analysis is essential.

\section{4-segment FS}

The speckle-tracking technique was employed to automatically trace the endocardial border of each ventricle, and FetalHQ was used to automatically calculate the 24-segment FS of each ventricle. ${ }^{16}$ Fractional shortening was calculated in each segment as follows: $\mathrm{FS}=[($ end-diastolic dimension $)-$ (end-systolic dimension) $]$ / (end-diastolic dimension) $\times 100$ (Fig. 12).

The reproducibility of 24-segment FS of the fetal heart using FetalHQ was previously reported to be fair by Hata et al. ${ }^{25} \mathrm{However}$, 


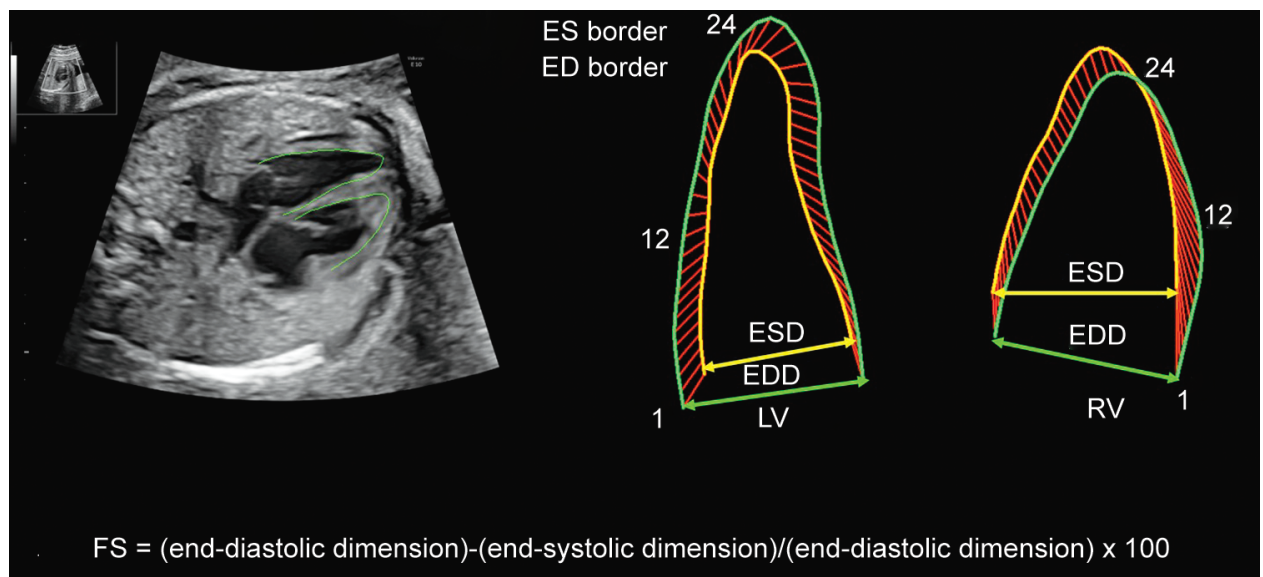

Fig. 12: Measurement of 24-segment fractional shortening (FS) at 26 weeks and 2 days of gestation. EDD, end-diastolic dimension; ESD, end-systolic dimension; LV, left ventricle: RV, right ventricle

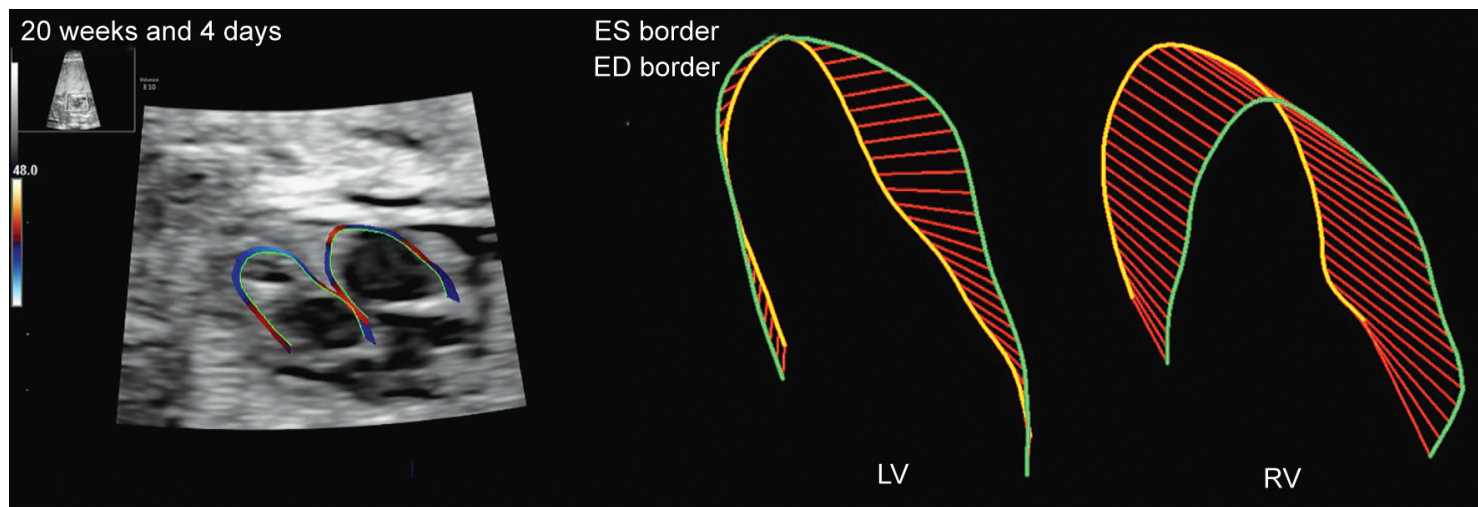

Fig. 13: FetalHQ graphics using a speckle-tracking technique of congenital complete heart block at 20 weeks and 4 days of gestation. LV, left ventricle: $R V$, right ventricle

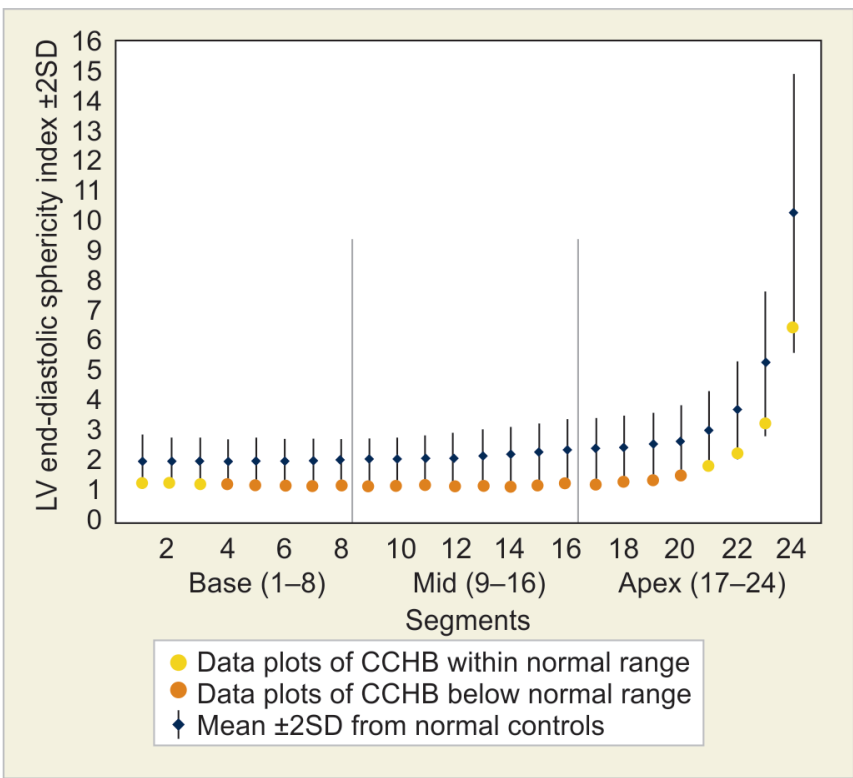

Fig. 14: Fetal 24-segment sphericity index (SI) of the left ventricle (LV) in a fetus with congenital complete heart block (CCHB) at 20 weeks and 4 days of gestation. Normal range is incorporated within the machine
FS values, particularly that for the right ventricle, may significantly differ with advances in gestational age.

Regardless of Doppler findings on the pulsatility index of the umbilical artery and/or the cerebroplacental ratio, the rate of abnormal 24-segment FS was previously reported to be high in fetuses with an estimated weight $<10$ th centile. ${ }^{26}$

A twin-twin transfusion syndrome recipient who underwent laser surgery exhibited cardiac remodeling in the basal segments of the right and left ventricles with improvements in biventricular function. $^{27}$

\section{Congenital Complete Heart Block}

A fetus with congenital complete heart block (CCHB) with heart failure (hydrops fetalis) at 20 weeks and 4 days of gestation (Fig. 13) had left ventricular segment 4-20 SI values (Fig. 14) and right ventricular segment 1-8 SI values (Fig. 15) that were below the normal ranges. Left ventricular segment 1-4 and 9-12 FS values (Fig. 16) and all right ventricular FS values on apex segments (segments 17-24) (Fig. 17) were also below the normal ranges.

\section{Conclusion}

Recent advances in ultrasound techniques such as HDlive Flow (silhouette) and FetalHQ for fetal echocardiography have 


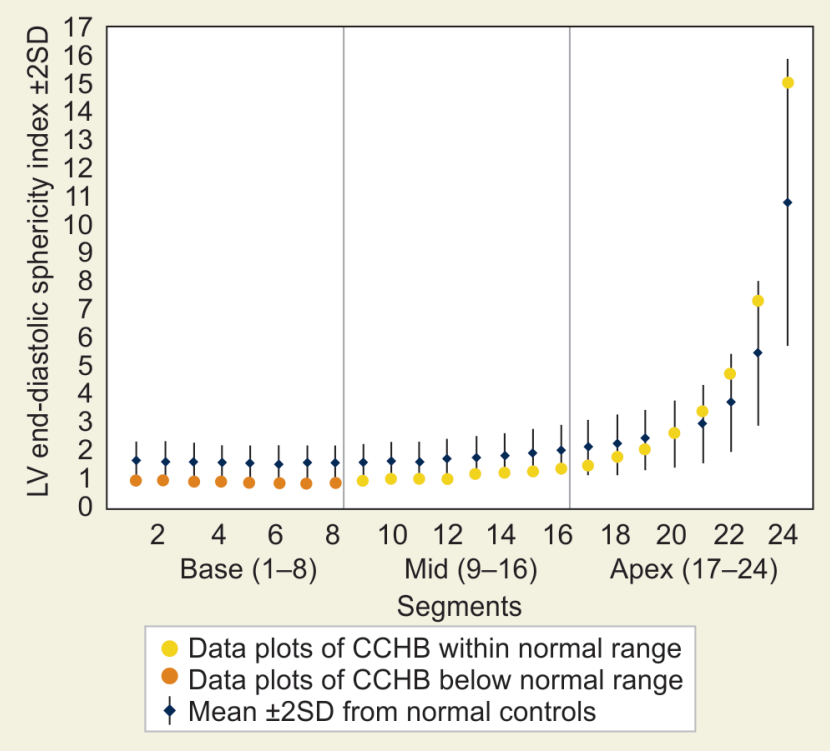

Fig. 15: Fetal 24-segment sphericity index (SI) of the right ventricle (RV) in a fetus with congenital complete heart block (CCHB) at 20 weeks and 4 days of gestation. Normal range is incorporated within the machine

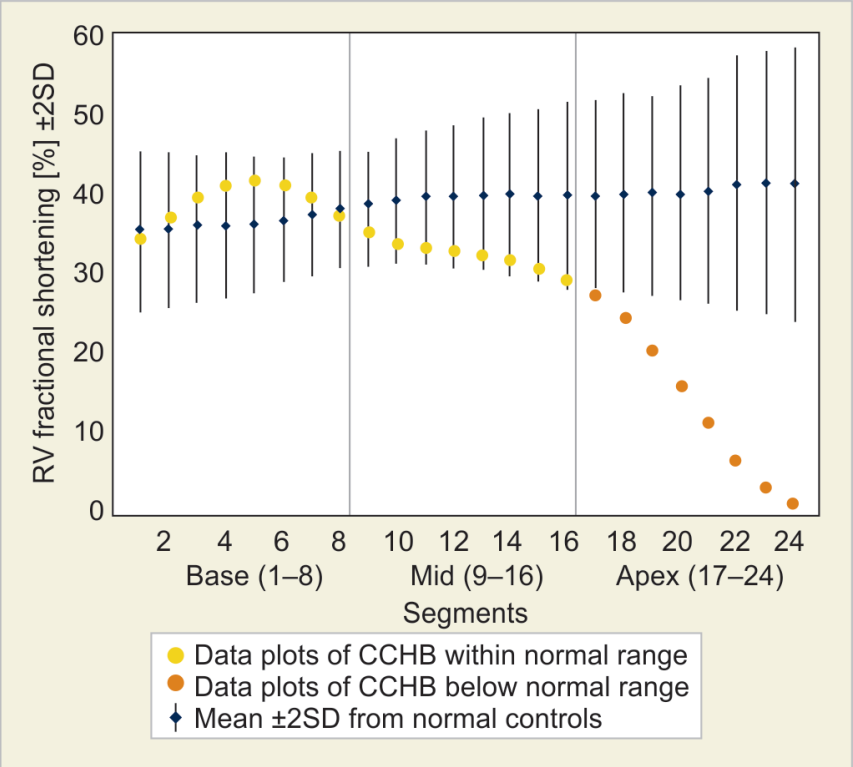

Fig. 17: Fetal 24-segment fractional shortening (FS) of the right ventricle (RV) in a fetus with congenital complete heart block (CCHB) at 20 weeks and 4 days of gestation. Normal range is incorporated within the machine

been developed. HDlive Flow (silhouette) with STIC generates important information, and its use alongside conventional 2D fetal echocardiography should be recommended while diagnosing congenital heart disease in research and clinical settings. HDlive Flow (silhouette) with STIC may become an important diagnostic adjunct while assessing the normal fetal heart and congenital heart anomalies.

In the future, Feta/HQ may become a useful diagnostic modality for assessing fetal cardiac remodeling and contractility while

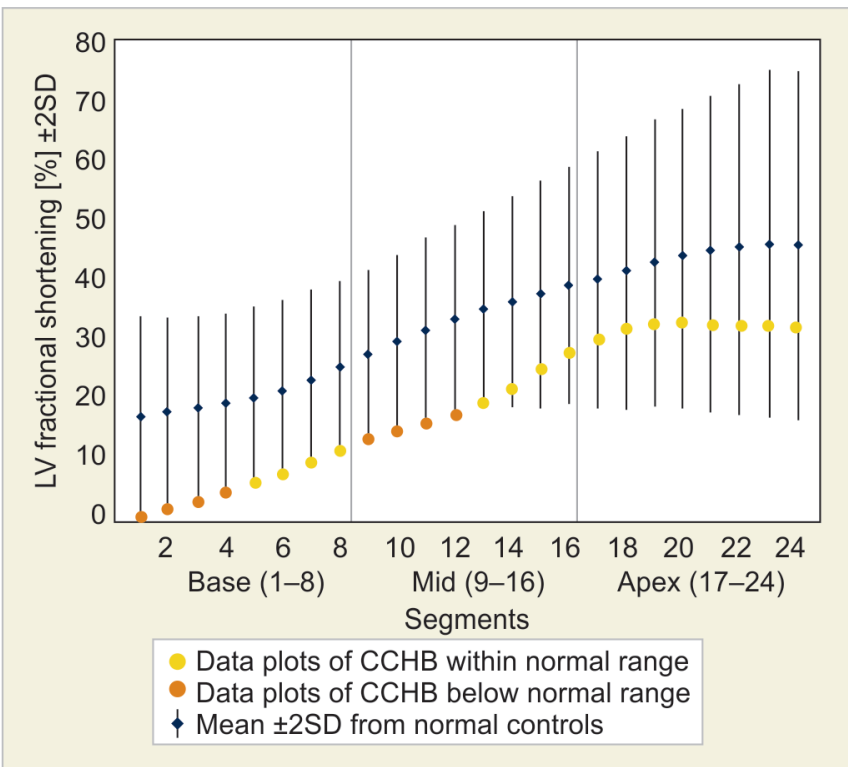

Fig. 16: Fetal 24-segment fractional shortening (FS) of the left ventricle (LV) in a fetus with congenital complete heart block (CCHB) at 20 weeks and 4 days of gestation. Normal range is incorporated within the machine

examining the fetal heart. Irrespective of these advantages, these techniques are associated with a marked learning curve, and many beginners and some experts may be unfamiliar with them. For their widespread application in clinical practice and research, further training is necessary.

\section{References}

1. AboEllail MAM, Kanenishi K, Tenkumo C, et al. Diagnosis of truncus arteriosus in first trimester of pregnancy using transvaginal fourdimensional color Doppler ultrasound. Ultrasound Obstet Gynecol 2015;45(6):759-760. DOI: 10.1002/uog.14868.

2. Hata T, AboEllail MAM, Sajapala S, et al. HDliveFlow in the assessment of fetal circulation. Donald School J Ultrasound Obstet Gynecol 2015;9(4):462-470. DOI: 10.5005/jp-journals-10009-1433.

3. AboEllail MAM, Kanenishi K, Tenkumo C, et al. Four-dimensional power Doppler sonography with the HDlive silhouette mode in antenatal diagnosis of a right aortic arch with an aberrant left subclavian artery. JUltrasound Med 2016;35(3):661-663. DOI: 10.7863/ ultra.15.05047.

4. Yang PY, Sajapala S, Yamamoto K, et al. Antenatal diagnosis of idiopathic dilatation of fetal pulmonary artery with 3D power Doppler imaging. J Clin Ultrasound 2017;45(2):121-123. DOI: 10.1002/jcu.22367.

5. Ito M, AboEllail MAM, Yamamoto K, et al. HDlive Flow silhouette mode and spatiotemporal image correlation for diagnosing congenital heart disease. Ultrasound Obstet Gynecol 2017;50(3):411-415. DOI: 10.1002/uog.17519.

6. Hata T, Ito M, Nitta E, et al. HDliveFlow silhouette mode for diagnosis of ectopia cordis with a left ventricular diverticulum at 15 weeks' gestation. J Ultrasound Med 2018;37(10):2465-2467. DOI: 10.1002/ jum.14583.

7. Karmegaraj B, Rajeshkannan R, Kappanayil M, et al. Fetal descending aortic tortuosity with ductal aneurysm. Ultrasound Obstet Gynecol 2019;54(1):142-144. DOI: 10.1002/uog.20303.

8. Hata T, Hanaoka U, Kanenishi K. HDliveFlow silhouette mode for fetal heart. In Merz E, Kurjak A, ed. Donald School Textbook Current Status of Clinical Use of 3D/4D Ultrasound in Obstetrics and Gynecology. New Delhi: Jaypee Brothers Medical Publishers (P) Ltd.; 2018. pp. 137-151. 
9. Hata T. HDliveFlow for fetal heart. In Sen C, Stanojevic M, ed. Fetal heart: screening, diagnosis and intervention. New Delhi: Jaypee Brothers Medical Publishers (P) Ltd.; 2019. 201-217.

10. Tseng JJ, Peng HW, Jan SL. An in-depth perspective of aortic arch branching in fetal vascular rings using spatiotemporal image correlation combined with high-definition flow imaging. J Ultrasound Med 2019;38(8):2217-2224. DOI: 10.1002/jum.14891.

11. Ma B, Wu L, Zhang W. Rare vascular ring of right aortic arch and aberrant left subclavian artery in association with bilateral ductus arteriosus. Ultrasound Obstet Gynecol 2020;55(1):132-139. DOI: 10.1002/uog. 20365.

12. Hata T, Koyanagi A, Yamanishi T, et al. Success rate of five cardiac views using HDlive Flow with spatiotemporal image correlation at 18-21 and 28-31 weeks of gestation. J Perinat Med 2020;48(4):384-388. DOI: 10.1515/jpm-2019-0434.

13. Hata T, Koyanagi A, Yamanishi T, et al. THree-dimensional fetal echocardiographic assessment of persistent left superior vena cava with absent right superior vena cava. Donald School J Ultrasound Obstet Gynecol 2020;14(4):346-348. DOI: 10.5005/ jp-journals-10009-1671.

14. Takayoshi R, Hata T, Bouno S, et al. HDlive Flow for the diagnosis of double outlet right ventricle at 19 weeks of gestation. Donald School J Ultrasound Obstet Gynecol 2020;14(4):351-354. DOI: 10.5005/ jp-journals-10009-1673.

15. DeVore GR, Klas B, Satou G, et al. 24-segment sphericity index: a new technique to evaluate fetal cardiac diastolic shape. Ultrasound Obstet Gynecol 2018;51(5):650-658. DOI: 10.1002/uog.17505.

16. DeVore GR, Klas B, Satou G, et al. Twenty-four segment transverse ventricular fractional shortening. A new technique to evaluate fetal cardiac function. J Ultrasound Med 2018;37(5):1129-1141. DOI: 10.1002/jum.14455.

17. DeVore GR, Polanco B, Satou G, et al. Two-dimensional speckle tracking of the fetal heart. A practical step-by-step approach for the sonologist. J Ultrasound Med 2016;35(8):1765-1781. DOI: 10.7863/ ultra.15.08060.

18. Rodrigues-Lopes M, Cruz-Lemini M, Valenzuela-Alcaraz B, et al. Descriptive analysis of the different phenotypes of cardiac remodeling in fetal growth restriction. Ultrasound Obstet Gyneco 2017;50(2):207-214. DOI: 10.1002/uog.17365.

19. DeVore GR, Zaretsky M, Gumina DL, et al. Right and left ventricular 24-segment sphericity index is abnormal in small-for-gestational-age fetuses. Ultrasound Obstet Gynecol 2018;52(2):243-249. DOI: 10.1002/ uog. 18820.

20. Rizzo G, Mattioli C, Mappa I, et al. Hemodynamic factors associated with fetal cardiac remodeling in late fetal growth restriction: a prospective study. J Perinat Med 2019;47(7):683-688. DOI: 10.1515/ jpm-2019-0217.

21. Crispi F, Miranda J, Gratacos E. Long-term cardiovascular consequences of fetal growth restriction: biology, clinical implications, and opportunities for prevention of adult disease. Am J Obstet Gynecol 2018;218(2S):S869-S879. DOI: 10.1016/j. ajog.2017.12.012.

22. DeVore GR, Jone PN, Satou G, et al. Aortic coarctation: a comprehensive analysis of shape, size, and contractility of the fetal heart. Fetal Diagn Ther 2020;47(Suppl. 5):429-439. DOI: 10.1159/000500022.

23. DeVore GR, Haxel C, Satou G, et al. Improved detection of coarctation of the aorta using speckle tracking analysis of the fetal heart using last examination prior to delivery. Ultrasound Obstet Gynecol 2020;57(2):282-291. DOI: 10.1002/uog.21989.

24. Hata T, Koyanagi A, Yamanishi T, et al. Evaluation of 24-segment sphericity index of fetal heart using FetalHQ. J Matern Fetal Neonatal Med 2020;1-7. DOI: 10.1080/14767058.2020. 1856808.

25. Hata T, Koyanagi A, Yamanishi T, et al. A 24-segment fractional shortening of the fetal heart using FetalHQ. J Perinat Med 2020;49(3):371-376. DOI: 10.1515/jpm-2020-0246.

26. DeVore GR, Gumina DL, Hobbins JC. Assessment of ventricular contractility in fetuses with an estimated fetal weight less than the tenth centile. Am J Obstet Gynecol 2019;221(5):498.e1-498.e22. DOI: 10.1016/j.ajog.2019.05.042.

27. Harbison AL, Pruetz JD, Ma S, et al. Evaluation of cardiac function in the recipient twin in successfully treated twin to twin transfusion syndrome (TTTS) using a novel fetal speckle tracking analysis. Prenat Diagn 2020;41(1):136-144. DOI: 10.1002/pd.5835. 